\title{
Advanced Quantitative Spine Imaging
}

\author{
James F. Griffith, MB, BCh, BAO, MD (CUHK), MRCP (UK), FRCP (Edin), FRCR, FHKCR, FHKAM (Radiology) ${ }^{\circledR}$ \\ ${ }^{1}$ Department of Imaging and Interventional Radiology, Faculty of \\ Medicine, The Chinese University of Hong Kong, Hong Kong \\ Semin Musculoskelet Radiol 2020;24:413-427.

\begin{abstract}
Address for correspondence James F. Griffith, MB, BCh, BAO, MD (CUHK), MRCP (UK), FRCP (Edin), FRCR, FHKCR, FHKAM (Radiology), LG12 Cancer Centre, Prince of Wales Hospital, Shatin, NT, Hong Kong (e-mail: griffith@cuhk.edu.hk).
\end{abstract}

\begin{abstract}
Although advanced quantitative imaging may not be currently used to any degree in the routine reporting of spinal examinations, this situation will change in the not too distant future. Advanced quantitative imaging has already allowed us to understand a great deal more regarding spinal development, marrow physiology, and disease

Keywords

- spine

- imaging

- quantification pathogenesis. Radiologists are ideally suited to drive this research forward. To speed up this process and optimize the impact of studies reporting spine quantitative data, we should work toward universal standards on the acquisition of spine data that will allow quantitative studies to be more easily compared, contrasted, and amalgamated.
\end{abstract}

The spine is the part of the musculoskeletal system most conducive to, and most likely to benefit from, quantitative imaging. Computed tomography (CT) and, more particularly, magnetic resonance imaging (MRI) allow bone and soft tissues to be evaluated free from the superimposition, magnification, and obliquity errors of radiography. This, and new imaging interrogation techniques, has enabled a profusion of new spine imaging data to be realized. This review looks broadly at the current issues, reported data, and potential benefits of advanced quantitative spine imaging, specifically addressing those areas considered to be of highest clinical relevance.

\section{Uses of Quantitative Spine Imaging}

Quantitative imaging data can potentially be used in a variety of ways. ${ }^{1}$ On an individual patient basis, quantitative spine imaging data can be used in these arenas:

- Diagnosis by having a normal or reference population reference interval and comparing suspicious imaging features with these reference intervals, for example to diagnose developmental canal stenosis or cord atrophy.

- Stratifying disease severity according to predefined reference ranges as in stratifying bone loss by quantitative computed tomography (QCT) or stratifying sarcopenia or the degree of disk degeneration. Providing the patient with easily appreciable objective data as to, for example, their degree of disk degeneration or muscle mass relative to a matched population cohort.

- Monitoring disease progress or response to therapy as in, for example, new treatments for spinal cord injury.

- Predicting disease progress in the absence of intervention as in, for example, the likelihood of progressive canal stenosis following input of multiple quantitative data into a predictive model.

- Predicting outcome following intervention as in patients who have spinal cord decompression.

- Predicting risk in, for example, the risk of developing spinal cord injury if engaging in high-energy contact sports.

On a larger scale, quantifiable image data can be used in these situations:

- Define reliable normal and population reference intervals for relevant covariables such as sex, height, and age.

- Use investigative studies and big data research to define disease patterns, compare different populations, and provide valuable data on disease pathogenesis including early detection. This seems to be the main benefit of quantitative spine imaging.

When defining reference intervals for parameters such as developmental spinal canal stenosis, we should appreciate the difference between a normal sample and a population reference interval. ${ }^{2}$ For a disease with progressive deterioration such as disk degeneration or bone density, reference
Issue Theme Advanced Quantitative MSK Imaging; Guest Editors, Eric Y. Chang, MD and Edwin H.G. Oei, MD, PhD
Copyright (c) 2020 by Thieme Medical Publishers, Inc., 333 Seventh Avenue, New York, NY 10001, USA. Tel: +1(212) 760-0888.
DOI https://doi.org/ 10.1055/s-0040-1713608. ISSN 1089-7860. 
limits are usually obtained in normal young skeletally mature individuals, usually aged 20 to 30 years. "Abnormality" is then rather arbitrarily defined as a deviation $>1$ standard deviation (SD) or $>2$ SDs from this young Gaussian-distributed population mean as, for example, for the bone mineral density (BMD) T-score. Alternatively, higher than the 90th percentile or $>97 \%$ cutoffs can be used. ${ }^{3}$ The symptomatic and asymptomatic matched populations can be compared to help validate these cutoff values.

For diseases in which there is no known deterioration over time, such as developmental spinal canal size or facet joint orientation, a large cross section of the population of any age can be referenced before determining optimal arbitrary cutoff values. To include only asymptomatic subjects in this population, reference interval seems incorrect because this would, for example, if determining developmental spinal canal size, tend to favor patients with a developmentally normal or capacious spinal canal while conversely including only symptomatic patients would favor patients with a developmental spinal canal stenosis.

\section{Main Issues Limiting the More Widespread Use of Quantitative Spine Imaging}

Currently, three overriding issues limit the more widespread use of quantitative spine image data: data reliability, time utilization, and clinical relevance.

\section{Data Reliability}

The objective data provided should be precise, reproducible, and clinically relevant. ${ }^{1}$ One of the frustrating features currently of quantitative spine imaging is the variability of data reported by different, seemingly rigorously conducted studies. For example, comparing studies reporting cervical cord crosssectional area (CSA), two studies on asymptomatic European and Japanese subjects, respectively, reported values of $\sim 72$ to $79 \mathrm{~mm}^{2}$ for cervical cord CSA. ${ }^{4,5}$ Another study on asymptomatic Canadians reported values of $\sim 93$ to $97 \mathrm{~mm}^{2}$.

Because objective analysis of imaging-based research databases is normally undertaken by supervised research assistants, close supervision on how (e.g., slice selection, digital zooming, contrast adjustment) and where to obtain measures is critical. This is particularly pertinent for boundary demarcation in CSA measurements as, for example, whether spinal cord measurements are made at the outermost margin of the spinal cord or just outside the cord. Given $\pi r^{2}$, if the radius changes by $\mathrm{r} \pm \mathrm{x}$, then CSA will change by $(\mathrm{r} \pm \mathrm{x})^{2} .^{2}$ Because the structures involved are often small, important before data point placement would seem helpful. Even after thorough training, though, readers still tend to produce different readings because there is a tendency to draw lines between gray levels of anatomical structures differently. ${ }^{4}$ Also, small but statistically significant differences can exist between different MR imaging systems due to factors such as corrections of geographic distortion or systematic different placement of the patient. ${ }^{4}$

Given the level of high-resolution imaging data now achievable on all standard body CT and MR systems, the main reason for interstudy variability seems to be differences in measure- ment techniques such as using sagittal versus axial planes for anteroposterior (AP) diameters, true axial versus oblique axial planes, and variable placement of measurement points. Scientific publications showing precisely where measurements points were placed are very helpful, although articles often do not include such images. ${ }^{7}$ Ideally, like guidelines available on who should acquire dual-energy X-ray absorptiometry (DXA) or QCT measurements, internationally accepted standardized protocols should be devised for the acquisition and measurement of advanced spine imaging quantitative data. ${ }^{8}$ These guidelines could then be adopted into protocols of studies involving acquisition of quantitative spine imaging data. Until this is done, considerable interstudy variability is likely to persist.

\section{Time Utilization}

For quantitative imaging data to be integrated into clinical practice, such data need to be obtained in an automated fashion because manual measurements are too time consuming for everyday use. Objective analytical data will someday be produced automatically by computer analysis of spine imaging raw data and be available for review when constructing the standard radiologic report. There is little doubt this will be available in the future with a digital readout of quantifiable data referenced to population or normal intervals like serology laboratory reports. That said, in our experience, current automated image segmentation/quantification techniques in the spine are not up to speed, requiring considerable adjustment following initial automatic segmentation.

\section{Clinical Relevance}

Currently, little objective data are used in the day-to-day radiologic reporting of spine examinations because it is time consuming to obtain and of limited clinical relevance in the individual patient setting. Most of the measured variables can be readily reported in daily practice using semiquantitative descriptors such as minimal, mild, moderate, or severe or mild to moderate, for example. There is no doubt, however, that image quantification of the spine will become more widespread, more reliable, and more automated in the not too distant future. Radiologic reports will continue to be composed mainly of descriptive terminology as they are now with quantitative data providing additional backup information.

The remainder of this review looks at 13 specific aspects of quantitative spine imaging focusing mainly on age-related physiologic changes rather than disease-related changes.

\section{Developmental Cervical Spinal Canal Size}

To date, no disadvantage has been found in having a large spinal canal. All problems arise when the canal is too small to accommodate the spinal contents ( - Fig. $\mathbf{1})$. There are two components to spinal canal stenosis. The first is how large the spinal canal is when it is fully developed (i.e., developmental spinal canal size). ${ }^{9}$ Developmental canal narrowing is measured at the pedicle level removed from acquired degenerative narrowing that occurs at the diskovertebral level. The second is the degree of acquired spinal canal stenosis that occurs due to superimposed narrowing from, for example, disk herniation, 


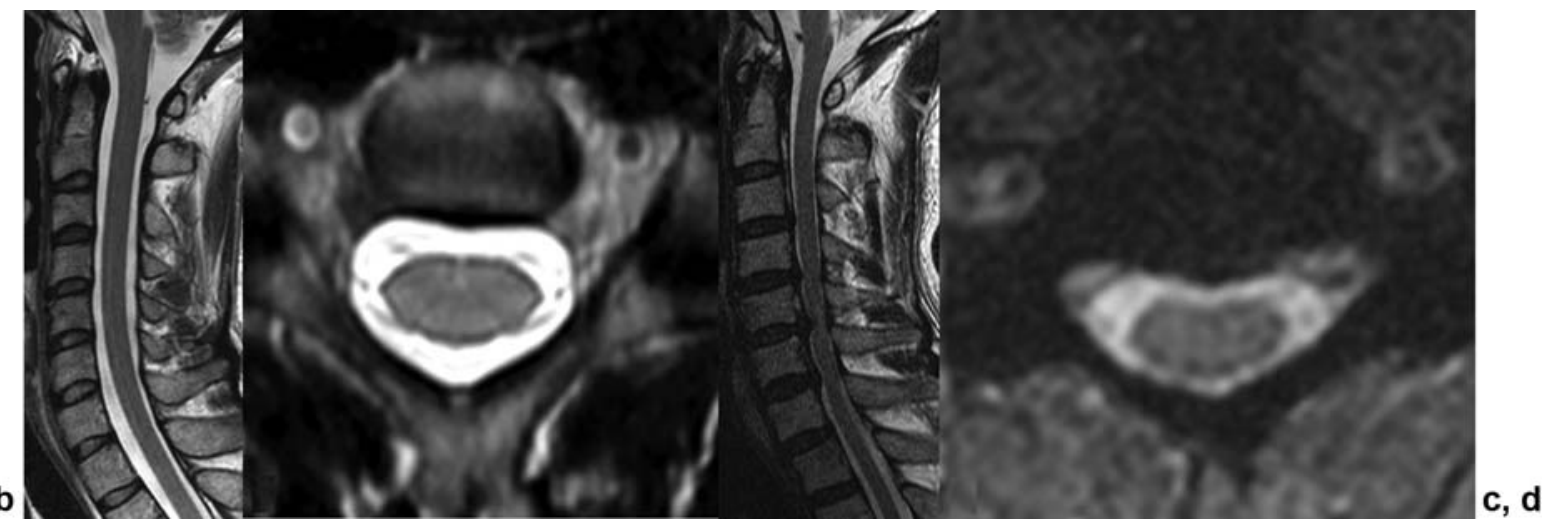

Fig. 1 (a) T2-weighted sagittal and (b) axial images of patient with developmentally normal caliber cervical spine compared with (c) T2weighted sagittal and (d) axial images of a patient with a developmentally small caliber cervical spinal canal. The patient with a developmentally small caliber cervical spinal canal has developed cord compression with only moderate disk bulging at C4-C5, C5-C6, and C6-C7.

osteophytosis, facet joint and capsular hypertrophy, ligamentum flavum hypertrophy, and spondylolisthesis.

Cervical myelopathy is usually due to acquired degenerative change superimposed on a developmentally small spinal canal. ${ }^{10}$ Patients with developmental canal stenosis tend to present 5.5 years earlier with degenerative cervical myelopathy and with worse baseline neurologic function. ${ }^{11}$ Regarding treatment, surgeons may be more inclined to undertake posterior decompression in patients with significant developmental spinal canal narrowing because it alleviates cord compression by canal expansion rather than by removal of the anterior compressive elements.

A developmentally small cervical spinal canal also predisposes to traumatic cord injury because it associated with smaller neural foramina, degenerative foraminal stenosis, and radiculopathy. A developmentally narrow canal may affect cervical kinematics and mechanical loading, potentially accelerating degenerative disease. ${ }^{12}$

Given the frequency of degenerative cervical myelopathy, canal measurements from $\mathrm{C} 3$ to $\mathrm{C} 7$ are the most useful. Reference intervals should be related to sex and height because these are the two variables that most influence cervical spinal canal size., ${ }^{43}$ Radiographic measures (i.e., the Pavlov-Torg ratio) do not correlate well with MR and CT, so radiography should not be relied on to determine cervical spinal canal stenosis. ${ }^{14-16}$ Spinal canal CSA can only be measured on axial images, but AP diameter can be measured on both sagittal and axial images. Sagittal and axial images yield comparable measures for spinal canal AP diameter with axial measurements possibly being very marginally $(\sim 1.5 \%)$ larger. ${ }^{4}$

From an MRI-based study of 140 white asymptomatic volunteers (mean age: 38 years; range: $18-78$ years), we can appreciate the considerable variability that exists for developmental cervical spinal canal size. ${ }^{4}$ For example, the AP diameter of the spinal canal, measured on axial images at the midvertebral body level, for a $1.7-\mathrm{m}$ tall woman was $12.5 \mathrm{~mm}$ (range: $9.5-16.5 \mathrm{~mm}$ ) at C3 and $12.2 \mathrm{~mm}$ (range: $9.3-16.1 \mathrm{~mm}$ ) at C6. ${ }^{4}$ This represents a $\sim 70 \%$ spread for AP diameter across the cohort.
An even greater variability in developmental canal size was seen for spinal CSA than AP diameter. ${ }^{4}$ For $1.7-\mathrm{m}$ tall women, spinal canal CSA was $189 \mathrm{~mm}^{2}\left(125-287 \mathrm{~mm}^{2}\right)$ at C3 and $177 \mathrm{~mm}^{2}\left(117-268 \mathrm{~mm}^{2}\right)$ at C6. This represents $\sim 120 \%$ for CSA across the cohort. In other words, developmental CSA varies more than AP diameter. Height has a much greater influence on canal AP diameter and CSA (both $<0.001$ ) than age $\left(0.042\right.$ and 0.031 , respectively) ${ }^{4}$

The normal values reported by Ulbrich et al would have been considered abnormal based on other study criteria. For example, in a study of 1,211 asymptomatic subjects, the mean AP diameter of the spinal canal at the C 5 mid-vertebral level was $15.8 \pm 1.5$ for all subjects, $16.2 \pm 1.5$ for men and $15.4 \pm 1.4$ for women. ${ }^{17}$ A developmentally narrow canal was defined as an AP diameter $<14 \mathrm{~mm},{ }^{17}$ which was present in $10 \%$ of subjects. In $0.5 \%$, the canal was $<12 \mathrm{~mm}$, in $2.4 \%$, it was $<13 \mathrm{~mm}$, and in $7.3 \%$, it was $<14 \mathrm{~mm}$. Elsewhere, developmental cervical canal stenosis was defined as a cervical canal diameter $<12$ to $13 \mathrm{~mm} .{ }^{18-20}$ Asymptomatic subjects with spinal cord compression or cord signal changes had significantly smaller cervical spinal canals than those without cord compression or cord signal change. ${ }^{13}$ The critical AP diameter below which cord compression was likely was $<14.8 \mathrm{~mm}$ in men and $<13.9 \mathrm{~mm}$ in women. ${ }^{13}$ We can appreciate even from these results the variability seen in reported data. These is a real need for population reference intervals to be established for different heights and sex and move away from the one-measurement-fits-all scenario.

Symptomatic patients show a much higher prevalence of developmental canal narrowing. For example, 50\% of symptomatic men and $78 \%$ of symptomatic women had an AP diameter of $<15 \mathrm{~mm}$ at the $\mathrm{C} 5$ mid-vertebral body level. ${ }^{13} \mathrm{~A}$ total of $68 \%$ of those patients with a narrow spinal canal $\left(<14 \mathrm{~mm}\right.$ AP diameter) were female. ${ }^{13}$ This sex difference reflects using the same criteria for men and women.

A study of CT imaging comparing cervical spine injured patients with control subjects concluded that the shape of the spinal canal and not the area put the patient at risk for spinal cord injury. ${ }^{7}$ The values for spinal canal size on this CT 
study were generally larger than the values reported from the MRI study. ${ }^{7}$ No comparative study comparing CT versus MRI in cervical spinal measurements has been performed.

\section{Cervical Spinal Cord Dimensions}

The spinal cord is malleable and changes shape to conform with the surrounding spinal canal configuration, from circular in the upper cervical region to ellipsoid coronally in the lower cervical region. ${ }^{4}$ Although sagittal images provide an indication of the likelihood of cord injury or compression, cord size should only be measured as cord CSA on axial images because cord AP diameter will give a false underestimation of cord size due to the change in cord shape.

When measuring the spinal cord, cadaveric studies can underestimate cord size measurements due to the effects to fixation and shrinkage. ${ }^{6}$ Also, for in vivo imaging, cord area tends to be slightly larger on T1-weighted rather than T2weighted axial images. ${ }^{21}$

Men have slightly larger $(\sim 3.5 \%)$ cervical cords than women.,5,21-24 Taller people also have larger spinal cords. ${ }^{4,22}$ The cervical spinal cord size reduced slightly in size with age ${ }^{25}$ in the order of $1 \%$ reduction in cord size per decade. ${ }^{6}$ Spinal cord size seems to remain relatively constant in size during flexion and extension. ${ }^{26}$ The largest CSA of the spinal cord seems to be at C4-C5 or C5-C6; the CSA of the spinal cord CSA at C3 and C6 is comparable. ${ }^{4-6}$

Comparing two separate studies that measured the spinal cord CSA in Japanese ${ }^{5}$ and in European ${ }^{4}$ volunteers, cervical spinal cord measurements were consistently $\sim 7 \%$ smaller for Japanese volunteers, which may be related to differences in height between both cohorts. So, for example, at C6, the difference in average spinal cord CSA for women was $68 \mathrm{~mm}^{2}$ versus $75 \mathrm{~mm}^{2}$; for men, it was $71 \mathrm{~mm}^{2}$ versus $77 \mathrm{~mm}^{2}{ }^{2,5}$

Within the same population cohort, the spinal cord does vary in size, but this variation is much less than that seen in spinal canal measurements. For 1.7-m tall European women, average spinal cord CSA was $75 \mathrm{~mm}^{2}\left(55-101 \mathrm{~mm}^{2}\right)$ at C3 and $75 \mathrm{~mm}^{2}\left(56-102 \mathrm{~mm}^{2}\right)$ at $66 .{ }^{4}$ This represents an approximate $40 \%$ spread in spinal canal CSA for C3 and C6 across the studied cohort. Because the variation in spinal canal CSA ( $\sim 120 \%$ ) is much greater than spinal cord CSA $(\sim 40 \%)$, spinal canal size has a much greater bearing on spinal cord to canal mismatch than spinal cord CSA.

The spinal cord occupation ratio (SCOR), which reflects the amount of spinal canal space occupied by the spinal cord, has been used as a measure of spinal cord to canal mismatch. ${ }^{5,22,27,28}$ Patients with spinal cord to canal mismatch are at risk of spinal cord injury, degenerative cervical myelopathy, and neurapraxia. This may be due to less cerebrospinal fluid around the cord, (1) making the cord more prone to degenerative encroachment, (2) reducing the ability to absorb kinetic forces that are transferred to the cord, (3) increasing the likelihood of venous congestive myelopathy, and finally (4) smaller cervical vertebrae may biomechanically be more prone to degeneration. ${ }^{12,29}$ Patients with spinal cord mismatch have worse baseline neurologic function. Because lower baseline neurologic function is a negative predictor of outcome, identification of a significant spinal cord mismatch may alter patient prognosis. ${ }^{11}$ Comparing SCORs in degenerative cervical myelopathy patients, the prevalence of mismatch was lower in Europe at 2.3\% compared with 10\% in Asia, Latin America, and North America. ${ }^{30}$ Routine assessment of developmental spinal canal stenosis may be indicated in those engaged in extreme and high-impact contact sports such as rugby, skiing, basketball, waterskiing, and football. Because there is relatively more space around the cord in taller patients, this probably puts a shorter person at higher risk of cervical cord compression. ${ }^{4}$

The three approaches to assessing spinal cord objectively are canal mismatch quantifying the (1) AP space around the cord as a ratio, (2) AP space around the cord as an absolute measure, or (3) CSA around the cord as a ratio. It is not known which of these approaches is best.

Using the first of these measures, spinal cord AP divided by spinal canal AP diameter, it was recommended that an SCOR $>75 \%$ (i.e., a cord occupying $>75 \%$ of the canal) at C5, which was close to $2 \mathrm{SDs}$ above the mean, should be used as an indicator of spinal canal to cord mismatch. ${ }^{5}$ Alternatively, averaging SCOR at the two most adjacent noncompressed sites in patients with degenerative cervical myelopathy, a SCOR $\geq 70 \%$ was used as an indicator of significant mismatch. ${ }^{31}$

The second approach is to subtract the spinal cord AP diameter from the canal AP diameter. ${ }^{32,33}$ In a retrospective analysis of cervical spine MRI examinations in athletes with and without neuropraxia, a value $<5 \mathrm{~mm}$ increased the likelihood of chronic neurapraxia risk, particularly if it was $<4.3 \mathrm{~mm}{ }^{32}$

The third approach is to compare CSAs on axial imaging. In a review of patients with minor cervical spine trauma, a SCOR $>80 \%$ on axial MRI could identify patients at risk for spinal cord injury. ${ }^{27}$

Therefore, to date, a spinal cord to canal mismatch can be categorized as a SCOR $\geq 75 \%$ for an AP ratio, $<5 \mathrm{~mm}$ for an AP absolute measure, and $\geq 80 \%$ for a CSA ratio. ${ }^{27,28,32}$ Clearly, SCOR at the moment can only be measured on MRI, whereas spinal canal dimensions can be measured on both MRI and CT. Spinal canal developmental size varies much more than spinal cord size. Whether spinal cord area is related to or independent of spinal canal area is not known. If the former is the case, the focus should be on spinal canal size rather than SCOR. If the latter is the case, it would seem reasonable to focus on SCOR.

\section{Cervical Vertebral Body Dimensions}

The volume of the cervical vertebrae is relevant to study of factors governing cervical vertebral body size as well as corpectomy and cage placement, among other things. Establishing reference standards for normal vertebrae and spinal dimensions can be achieved only after controlling for sex, age, and ethnicity due to the influence of these factors on vertebral anatomy. ${ }^{34}$ In a study of cervical vertebrae of 277 human skeletons born between 1825 and 1910, a detailed analysis of vertebral body dimensions showed that African Americans had significantly greater vertebral body width and depth in the C3C5 region than European Americans. ${ }^{34}$ The heights of the C3 and $\mathrm{C} 4$ vertebral bodies were significantly smaller in the African American population. Cervical vertebral bodies became 


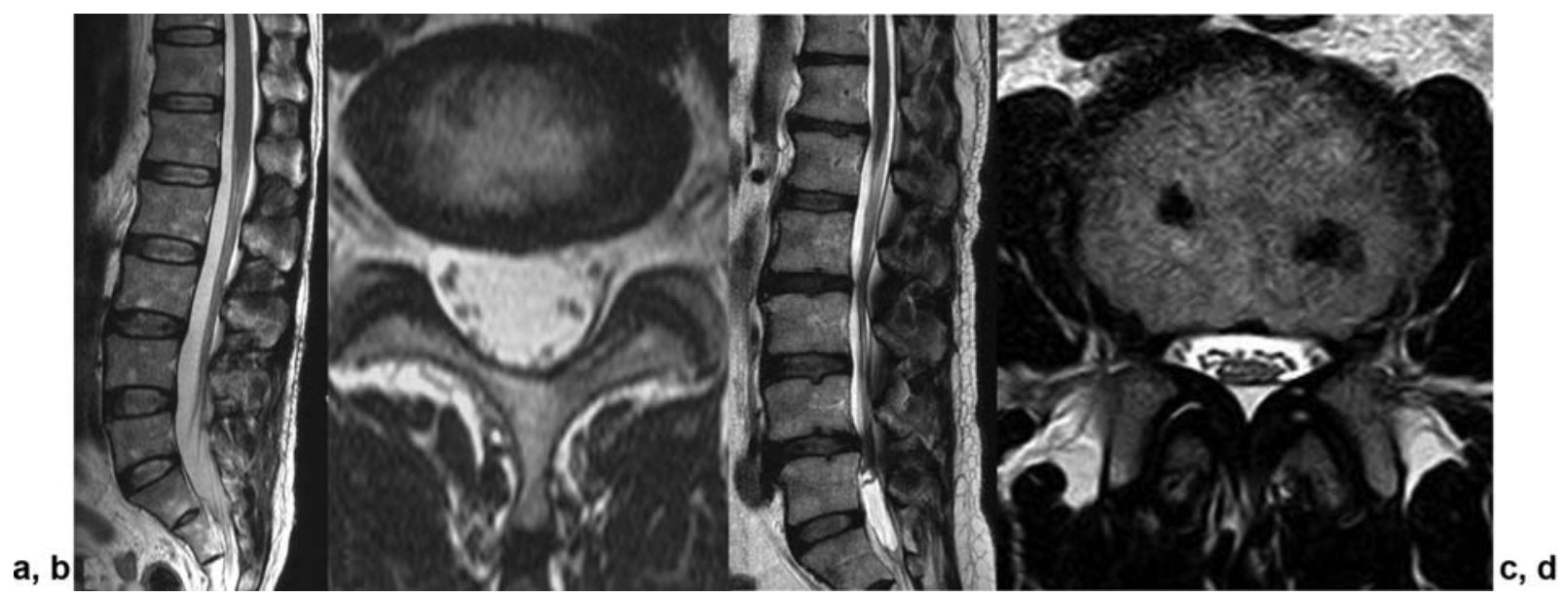

Fig. 2 (a) T2-weighted sagittal and (b) axial images of patient with developmentally normal caliber lumbar spinal canal compared with (c) T2weighted sagittal and (d) axial images of patient with developmentally small caliber lumbar spinal canal. The patient with a developmentally small caliber lumbar spinal canal has developed lumbar spinal canal stenosis due to only mild anterolisthesis and disk bulging at L4-L5.

wider and deeper with age with the changes in depth much more pronounced than the changes in width. ${ }^{34}$ There was a significant reduction in vertebral body height with age. ${ }^{34}$

That males have larger cervical vertebral bodies than females regardless of ethnic origin is well documented. ${ }^{35}$ While the height of the vertebral body decreases with age mainly between $\mathrm{C} 3$ and $\mathrm{C} 6$, the vertebral body expands. For example, in C3, between young and old patients, vertebral body width increased by $6 \%$ and vertebral body depth increased by $9 \%$, whereas at $\mathrm{C} 7$, width increased by $\sim 6 \%$ while depth increased by $\sim 15 \%{ }^{35}$ With advancing age, reduction in vertebral body height tends to be greater in women while the increase in vertebral body depth is similar for men and women. ${ }^{36}$ Because there is no change in the two measurements of the exit foramen with age, it can be concluded that most of the vertebral body expansion in depth seems to occur anteriorly. Another possible explanation for the changing vertebral body shape with age is the charge in cervical spine curvature that occurs to compensate for the increased thoracic kyphosis. ${ }^{37}$

\section{Developmental Lumbar Spine Canal Size}

Lumbar spinal canal stenosis is a common clinical entity. Similar to the cervical spine, two features govern the development of lumbar spinal canal stenosis: developmental lumbar spinal canal size and acquired narrowing of the lumbar spinal canal (-Fig. 2). It is important to separate these two elements when quantifying lumbar spinal canal size.

Developmental lumbar canal size relates to the size of the osseous spinal canal when spinal maturation is complete by the age of 17 years. It is unclear what factors govern lumbar spinal canal size, although it may be related to shorter gestation age, lower birth weight, primiparity, and lower socioeconomic class. ${ }^{38}$ Developmental lumbar spinal canal size is measured at the level of the pedicles removed from the acquired changes that predominate at the diskovertebral level (-Fig. 3). To develop population reference intervals, a large cross section of the population irrespective of symptoms must be studied. Using data obtained from abdominal pelvic CT examinations performed for reasons not related to the lumbar spine provides a good method of obtaining a
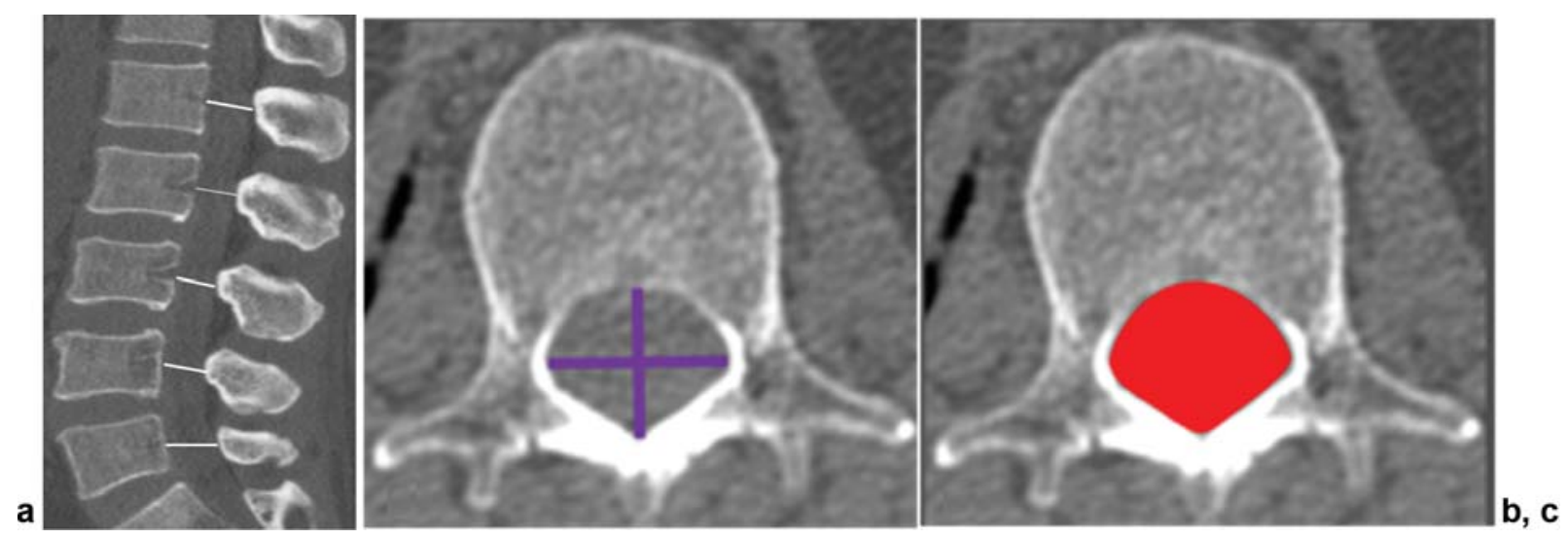

Fig. 3 (a) Developmental canal size is measured at the pedicular level removed from acquired degenerative narrowing that occurs at the diskovertebral level. (b) Anteroposterior and lateral diameters for lumbar developmental canal size. (c) Cross-sectional area for lumbar developmental canal size. 

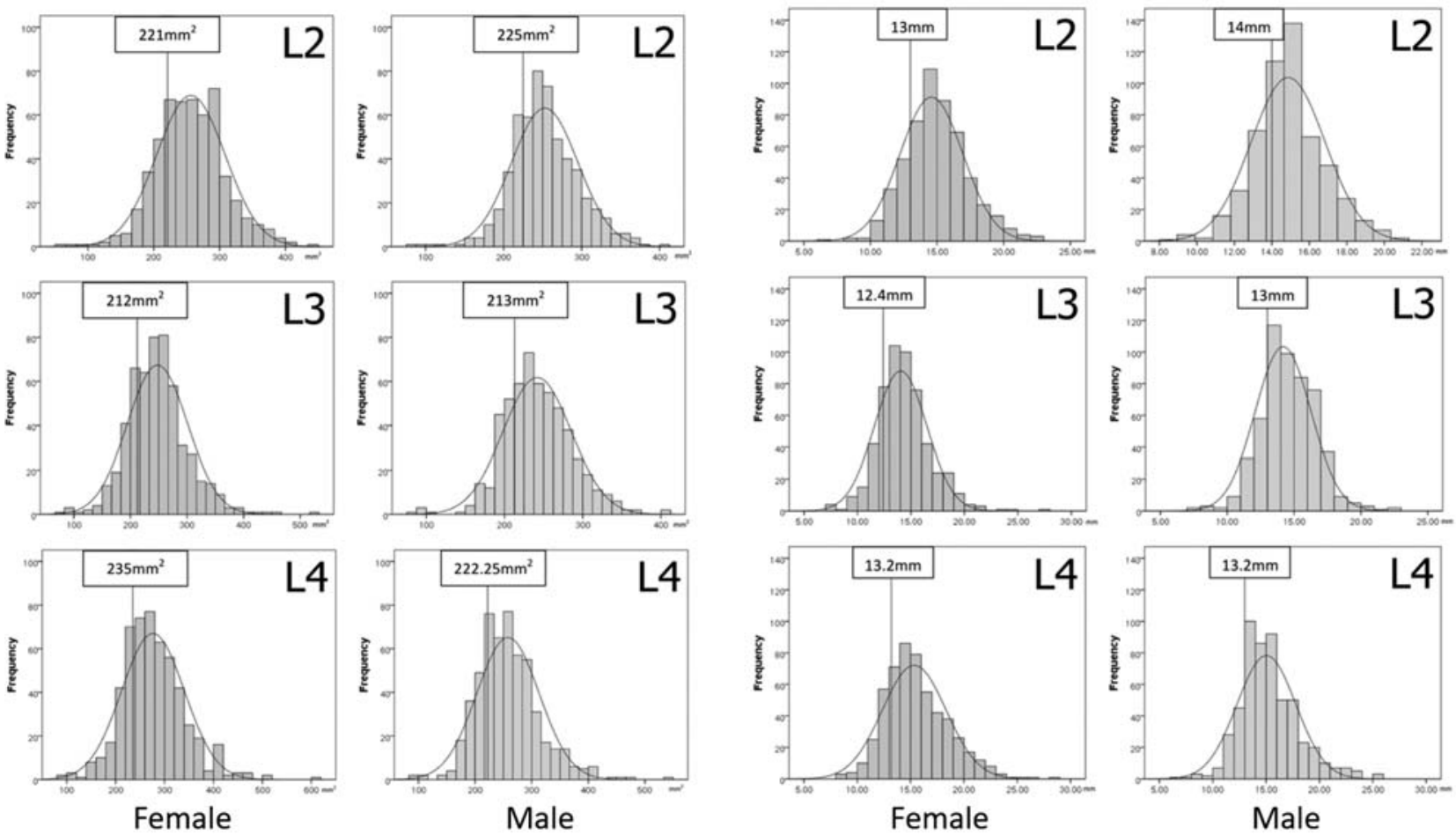

CSA

AP diameter

Fig. 4 Population reference intervals for lumbar developmental canal size for (a) cross-sectional area (CSA) and (b) anteroposterior (AP) diameter of the L2, L3, and L4 lumbar levels for females and males. The demarcation of the smaller quartile (i.e., smaller $25 \%$ ) at each level is indicated (modified from Griffith et $\mathrm{al}^{40}$ ).

population reference range for spinal dimensions with no need for additional specific imaging ${ }^{39,40}$ (- Fig. 4).

Such an approach could be undertaken for each region, race, and sex because considerable cross-population variation does seem to exist in patients with smaller lumbar spinal canals who are more likely to develop symptoms and require surgical intervention. ${ }^{39-41}$ Using this approach, a large (at least 34\% between largest and smallest quartiles) variation in lumbar developmental spinal canal CSA can be appreciated. ${ }^{40}$ Spinal canal CSA and depth is consistently smallest at L3, enlarging cranially and caudally within the lumbar region. ${ }^{40}$ There is no accepted definition of what defines a normal or abnormal spinal canal size. ${ }^{42}$ An L3 anteroposterior diameter $<13 \mathrm{~mm}$ for males and $<12.4 \mathrm{~mm}$ for females represented the smallest $25 \%$ for a southern Chinese population. ${ }^{40}$ Similarly, an osseous spinal canal $<212 \mathrm{~mm}^{2}$ for males and $<213 \mathrm{~mm}^{2}$ for females represented the smallest $25 \%$ of the population. ${ }^{40}$

\section{Lumbar Vertebral Body Dimensions}

The volume of the thoracic and lumbar vertebral bodies is relevant to vertebroplasty and other procedures. Using CTbased technique, verified by analysis of saw bone vertebral bodies, vertebral body volume increased from T1 to L4 for both female and male subjects. ${ }^{43}$ Mean thoracic vertebral body volume was $\sim 15.0 \mathrm{~cm}^{3}$; mean lumbar vertebral body volume was much higher at $\sim 35 \mathrm{~cm}^{3} .{ }^{43,44}$ Considerable individual variation in vertebral body size was present ranging from $5.2 \mathrm{~cm}^{3}$ for a T1 vertebral body to $60.6 \mathrm{~cm}^{3}$ for a L4 vertebral body. ${ }^{43}$ Vertebral body volume in men was larger than that of women only in the lumbar spine, mainly accountable by an increase in vertebral body CSA. ${ }^{45}$ Although thoracic and lumbar vertebral body height is, as expected, closely related to patient height, lumbar vertebral body CSA in males is related to patient weight. ${ }^{45}$ The L5 vertebral body volume is normally up to $5 \%$ smaller than the L3 or L4 vertebral bodies. ${ }^{43,44}$ Patients with 55 pars defects tend to have even smaller L5 vertebral bodies, $\sim 10 \%$ smaller than $L 4$, with greater posterior wedging. ${ }^{44}$

\section{Bone Mineral Density}

BMD is the most important surrogate marker of bone strength. It is most widely measured by DXA, although this is an areal rather than volumetric assessment measuring both cortical and trabecular BMD. ${ }^{46}$ Trabecular volumetric BMD (vBMD) by single-energy QCT is a more accurate, although less practical, reference standard for noninvasive vBMD assessment. ${ }^{47}$ With QCT, osteopenia is defined as a trabecular BMD $<120 \mathrm{mg} / \mathrm{cm}^{3}$; osteoporosis is defined as a trabecular BMD $<80 \mathrm{mg} / \mathrm{cm}^{3} .8$ Radiation dose for lumbar $\mathrm{QCT}$ is $\sim 1 \mathrm{mSv}$ for men and $1.6 \mathrm{mSv}$ for women, many times

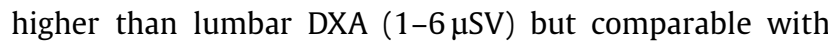
lumbar spine radiography (0.7-2 MSv). ${ }^{47,48}$

Using spectral detection CT as a feature of dual-energy CT, vBMD can be quantified without using a calibration phantom ("phantomless") yielding high correlation with standard QCT assessment $(\mathrm{r}=0.987){ }^{49}$

Partial volume averaging due to bone voxels that contain fat will reduce trabecular vBMD measurement by single- 
energy QCT by $\sim 15 \%{ }^{50} \mathrm{~A}$ method to correct single-energy QCT for marrow fat content was also recently developed. ${ }^{51}$ After first adjusting manufacturer-calibrated values for the European Spine Phantom (ESP-145), density measurements can be adjusted to account for bone marrow adipose tissue (BMAT) content as measured by MRI as follows:

vBMD BMATcorr $=\mathrm{vBMD} \quad$ ESPcorr $+0.7576 \times$ BMAT $(\%)-$ $12.96\left(\mathrm{mg} / \mathrm{cm}^{3}\right)$.

After correcting for marrow fat content, mean L2-L4 vertebral body vBMD decreased in women from 20 to 80 years by $-2.57 \pm 0.11 \mathrm{mg} / \mathrm{cm}^{3} /$ year, $\sim 15 \%$ less than the uncorrected value $\left(-3.00 \pm 0.13 \mathrm{mg} / \mathrm{cm}^{3} /\right.$ year $)$. Mean vBMD annual decrease for men was $-1.70 \pm 0.14 \mathrm{mg} / \mathrm{cm}^{3} /$ year, $\sim 10 \%$ less than the uncorrected value $\left(1.92 \pm 0.15 \mathrm{mg} / \mathrm{cm}^{3} / \text { year }\right)^{51}$ Dual-energy CT can also accurately measure marrow fat content and enable correction of QCT vBMD data accordingly. ${ }^{50,52}$

Bone islands are much more common than sclerotic metastases and tend to have higher bone density. ${ }^{53,54}$ This density difference can be used to distinguish bone island and sclerotic metastasis with a high level of certainty. This is done by drawing a region of interest (ROI) as large as possible on the lesion without extending beyond the lesion's margins, irrespective of whether intravenous contrast was administered or not. Either a mean attenuation $\geq 885 \mathrm{HU}$ or a maximum attenuation $\geq 1,060 \mathrm{HU}$ for the lesion has a sensitivity of $95 \%$ and specificity of $96 \%$ for diagnosing a bone island. $^{53}$

\section{Marrow Fat Content and Composition}

Magnetic resonance spectroscopy (MRS) can measure bone marrow fat composition as well as content but is limited in allowing assessment of only one vertebral body. Single-voxel MRS-based marrow fat quantification should ideally be based on a multi-TE MRS measurement to minimize confounding effects on proton-density fat fraction and water fractions. ${ }^{55}$

Chemical shift encoded separation techniques (fat-water imaging) can also accurately measure marrow fat content and has a shorter acquisition time of 3 to 4 minutes across a wider scan plane, although it cannot assess marrow fat composition. ${ }^{56-58}$ The reproducibility of ${ }^{1} \mathrm{H}$ MR spectroscopy and chemical-shift imaging is high, tending to be best in those areas with the highest inherent fat fraction. ${ }^{59-61} \mathrm{~A}$ standardized T1-signal intensity can also be measured, that is, the vertebral marrow to subcutaneous fat ratio. ${ }^{62} \mathrm{Al}-$ though straightforward, accuracy is compromised because T1 signal intensity depends on factors such as coil position, saturation band positioning, and postprocessing homogenization of B1 inhomogeneity, in addition to marrow fat. ${ }^{62}$

Marrow fat content increases from the cervical to the lumbar spine. ${ }^{61,62}$ When comparing fat measurements between studies, we need to consider from which vertebrae were taken. The L3 vertebral body is the most usually measured, although the T11 and L1 vertebral bodies may be more representative. ${ }^{62,63}$

There is a gradual physiologic increase in vertebral marrow fat content with age, from $\sim 25 \%$ marrow fat content at 25 years to $65 \%$ at 65 years. ${ }^{64,65}$ This increase is different in

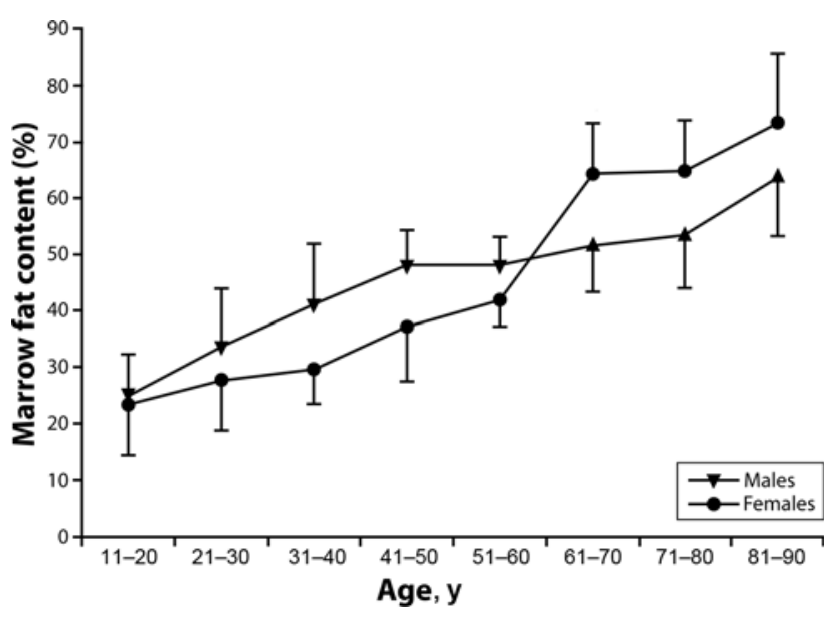

Fig. 5 Marrow fat content, \% of lumbar vertebral body stratified for age and sex. Throughout life, marrow fat increases slowly and steadily for both sexes with a dramatic increase in marrow fat content between the ages of 55 and 65 years for women. This mirrors the reduction in bone mineral density that occurs at that time in women.

males and females. Males show a gradual increase of $7 \%$ per decade in lumbar vertebral marrow fat content; females show an increase of $\sim 5 \%$ per decade up to 55 years followed by a dramatic increase in marrow fat content between 55 and 65 years of $\sim 25 \%{ }^{64,66}$ ( - Fig. 4). Male lumbar vertebrae have $\sim 10 \%$ more fat than females up to 50 years. ${ }^{64}$ Between 50 and 60 years, this sex difference narrows and disappears. ${ }^{64}$ After 60 years, females have $\sim 10 \%$ more marrow fat in their vertebrae than males ${ }^{66}$ (-Fig. 5).

Overall, there is at least a 40 to $50 \%$ increase in fat cell content with increasing age. This increase in fat content happens primarily due to an increase in fat cell number rather than fat cell size, ${ }^{67}$ and it seems to be associated with little, if any, change in marrow fatty acid profile. ${ }^{68}$ This increase in fat cell volume occurs primarily at the expense of red marrow volume. Although the trabecular volume decreases with age, the overall percentage decrease in trabecular volume is small at $\sim 5 \%$ in volume. Because the marrow cavity is a defined space and vascular sinusoids and other marrow structures do not seem to expand with age, we can infer that for any increase in fat cell content, there is almost a corresponding decrease in functioning or red marrow content. In other words, marrow fat content should be a good surrogate marker for hematopoietic marrow content (- Fig. 6). ${ }^{69}$

The inverse relationship between increasing marrow fat and trabecular bone loss in osteoporosis has been recognized histologically for 50 years. ${ }^{70}$ MRI, and more recently dualenergy $\mathrm{CT}$, have enabled marrow fat content to be quantified noninvasively on a large scale and at different anatomical sites. $^{52}$ Over and above the physiologic increase in marrow fat content with age, osteoporosis is associated with an even greater increase in marrow fat content for both males and females. Using MRS, marrow fat content in older men with normal BMD, osteopenia, and osteoporosis was $50.1 \pm 8.7 \%$, $55.7 \pm 10.2 \%$, and $58.2 \pm 7.8 \%$, respectively $(p=0.002) .{ }^{71}$ Similarly, for older women, marrow fat content in those with normal BMD, osteopenia, and osteoporosis was $59.2 \pm 10.0 \%$, 


\section{young}

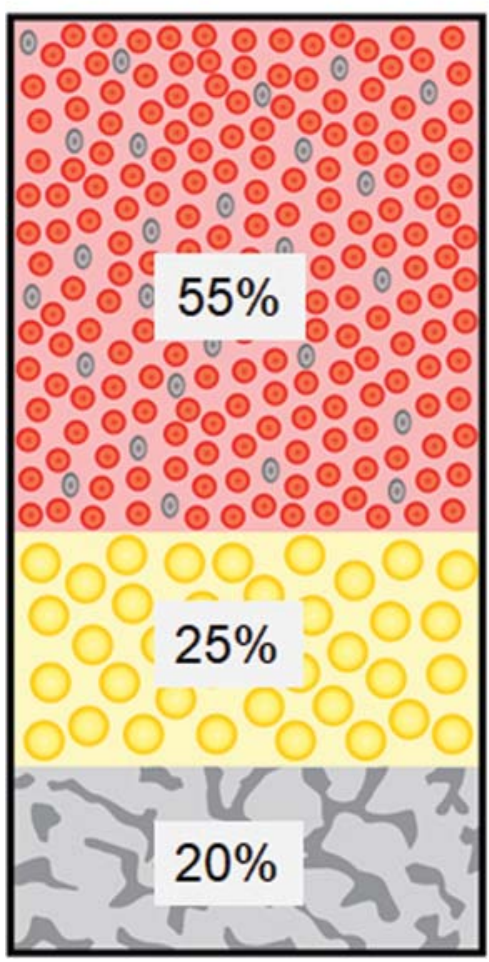

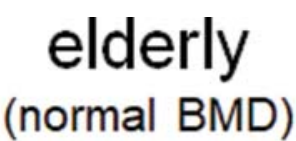

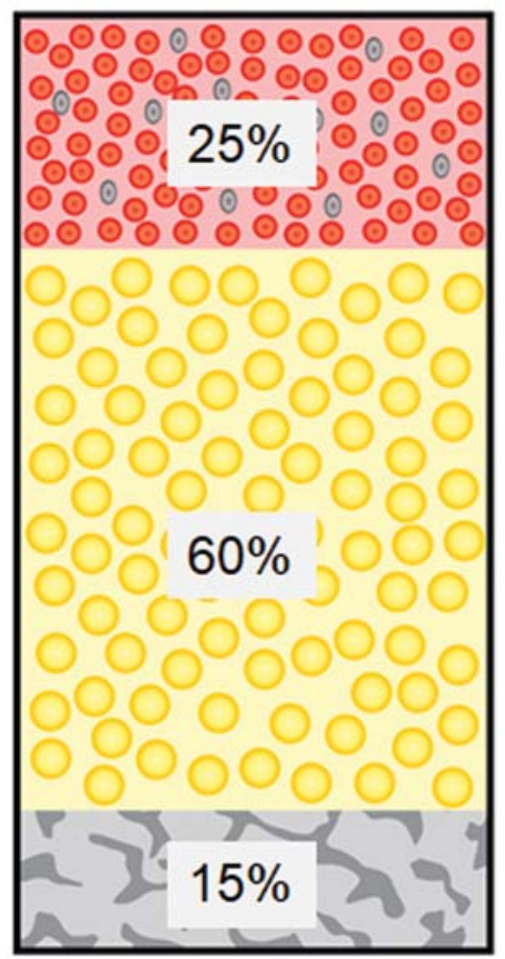

elderly

(osteoporosis)

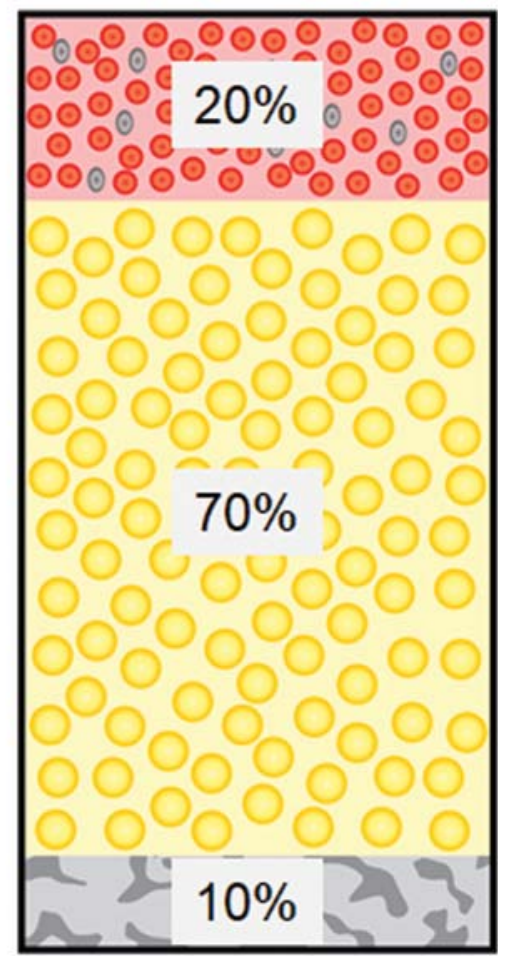

Fig. 6 The bone marrow is confined by the rigid bone cortex. As marrow fat content increases with age, red marrow content decreases because any age-related with or without osteoporotic-related change in trabecular bone volume is relatively small. In other words, marrow fat content is a surrogate marker of red marrow fat content. Physiologic changes in bone marrow content are exaggerated in patients with osteoporosis. BMD, bone mineral density.

$63.3 \pm 9.5 \%$, and $67.7 \pm 8.5 \%$, respectively $(p=0.002) .{ }^{72}$ Similar results were shown using three-dimensional gradient-echo chemical-shift-encoded fat-water imaging. ${ }^{56}$ In a study of 51 patients (28 females; mean age: $69.7 \pm 9.0$ years), mean fat content of normal BMD vertebrae $(56.3 \pm 14.8 \%)$ was higher than that of osteoporotic vertebrae $(62.4 \pm 11.0 \% ; p=0.007) .{ }^{56}$ Trabecular bone loss, which can be specifically measured by QCT, as opposed to DXA that usually measures both trabecular and cortical bone loss, seems to be much more associated with increased marrow fat content than cortical bone loss. ${ }^{73}$

Higher prevalent marrow fat predicts future increased osteoporotic bone loss. Postmenopausal women with a marrow fat content above the median experienced average bone loss of $4.7 \%$ over 4 years, whereas those with a marrow fat content below the median only experienced bone loss of $1.6 \%{ }^{74}$ Similarly, for each 1 SD ( 8\%) increase in baseline marrow fat content, trabecular vBMD tended to increase by $\sim 0.9 \%$ more over a 3 -year period. ${ }^{75}$

Increased marrow fat may also increase vertebral fracture risk. Mean vertebral marrow fat was $55 \%$ in those with a prevalent vertebral fracture compared with $45 \%(p<0.001)$ in those without a prevalent vertebral fracture even after adjusting for the effect of marrow fat on DXA measurements. ${ }^{76}$ To date, no longitudinal studies have investigated whether marrow fat content is related to incident vertebral fracture. ${ }^{73}$ In addition, osteoporosis marrow fat is also increased in other conditions associated with reduced BMD such as anorexia nervosa, alcohol abuse, spinal cord injury, and prolonged bed rest. ${ }^{52}$

Although chronic osteoporotic-type fractures can be readily recognized on MRI, quantitative MR imaging can be helpful in distinguishing between acute/subacute vertebral fracture and malignant fracture. The presence of fat within the fractured vertebral body on T1-weighted images is very helpful sign in identifying the fracture as osteoporotic. ${ }^{77}$ In equivocal cases, chemical shift fat to water imaging can augment standard imaging in quantifying fat content within the fractured vertebral body. Either the absolute fat content or a fat fraction ratio can be used where the fat content of the fractured vertebral body is compared with the fat content of an adjacent normalappearing vertebral body. A fat fraction $<9 \%$ within the fractured vertebral body or a fat fraction ratio $<0.2$ indicates malignancy with a $96 \%$ sensitivity and $89 \%$ specificity. ${ }^{78,79}$

MRS can also evaluate fat composition. The portion of unsaturated vertebral marrow fat in healthy young subjects was higher than postmenopausal osteoporotic women ( 0.127 versus 0.091$),{ }^{80}$ a finding confirmed by spectroscopy of iliac crest aspirates. ${ }^{73}$ Patients with prevalent vertebral fracture patients have $1.7 \%$ lower unsaturation levels and 2.9\% higher vertebral marrow fat saturation levels than those with no fracture. ${ }^{81}$ People with diabetes also had $1.3 \%$ lower unsaturation and 3.3\% higher vertebral marrow fat saturation levels, 
whereas diabetic patients with fracture had the lowest marrow unsaturation and highest saturation. ${ }^{81}$ Diabetes may change marrow fat composition but have little or no effect on marrow fat content. ${ }^{81}$

\section{Bone Marrow Perfusion}

MRI can measure marrow perfusion with high reproducibly using empirical time-intensity curve measures such as maximal enhancement (Emax) and enhancement slope (Eslope). ${ }^{60}$ Pharmacokinetic modeling can also be applied, although these measures are less robust and more theoretical. Within the rigid confines of the bone cortex, because the two main constituents of bone marrow are red and fatty marrow, fatty marrow content is a surrogate marker for red marrow content. In other words, the higher the fatty marrow content, the lower the red marrow content. Red marrow, being much more metabolically active than fatty marrow, is the main driver of bone marrow perfusion. Therefore, as expected, changes in bone marrow perfusion coincide well with changes in red marrow content. ${ }^{67}$ Bone marrow perfusion is also related to endothelial dysfunction and atherosclerosis with a weak negative correlation $(r=-0.33 ; p=0.0018)$ between vertebral body perfusion and carotid artery intima media thickness. ${ }^{82}$

Vertebral marrow perfusion reduces with aging. ${ }^{83-87}$ Overall Emax was $>60 \%$ greater in subjects aged $<50$ years $(58.2 \pm 44.6)$ than subjects aged $>50$ years $(21.9 \pm 14.8) .{ }^{83}$ For females only, an even greater difference was apparent with Eslope in those $<50$ years $(87.2 \pm 54.1)$ being $80 \%$ greater than those $>50$ years $(18.0 \pm 13.8) .{ }^{83}$ Although vertebral bone marrow perfusion is higher in young females than young males, the rate of perfusion decline is also higher in females, such that vertebral bone marrow perfusion is higher in older men than older women. ${ }^{83}$ This pattern closely matches changes that occur in red to fatty marrow composition with age. Also, in line with changing marrow fat content, the upper (L1-L2) lumbar vertebral bodies are better perfused than the lower (L3-L5) vertebral bodies. ${ }^{85,86}$

Bone perfusion is also closely related to BMD. As BMD decreases, marrow fat increases. Patients with osteoporosis have lower bone marrow perfusion than those with osteopenia, whereas patients with osteopenia have lower bone marrow perfusion than those with normal $\mathrm{BMD}^{88}$ (-Fig. 7). This reduction in perfusion affects the marrow but not the surrounding muscle, indicating it is an integral marrow effect rather than part of a more generalized circulatory impairment. ${ }^{72}$ Bone perfusion is a critical element in bone fracture healing including microfracture healing. Wee can appreciate how compromised perfusion in osteoporotic bone could lead to impaired microfracture healing and thus to microfracture propagation until a spontaneous macroscopic insufficiency fracture occurs, occasionally followed by fracture nonunion. ${ }^{88,89}$

\section{Bone Marrow Diffusion}

Free movement of extracellular water molecules in the bone marrow is affected by the cellular compaction and the amount of interstitial fluid. Extracellular water motion also depends on factors such as blood flow, capillary permeability, interstitial pressure, temperature, and the viscosity of interstitial fluid. The standard measure of water diffusivity in tissues is the apparent diffusion coefficient (ADC) acquired from single-shot echo planar imaging. The ADC of water is $3.0 \times 10^{-3} \mathrm{~mm}^{2} / \mathrm{s}$. The ADC of bone marrow is the lowest of nearly all tissues at 0.20 to $0.60 \times 10^{-3} \mathrm{~mm}^{2} / \mathrm{s}$, and particularly fatty marrow that has an ADC about half that of red marrow. ${ }^{90-92}$

Overall, ADC values tend to decrease with increasing age; the correlation ( $\mathrm{r}=-0.3$ to $-0.4 ; p=0.001$ ) is weak. . $^{93,94}$ Mean vertebral ADC values in subjects aged $<30$ years $\left(0.54 \pm 0.07 \times 10^{-3} \mathrm{~mm}^{2} / \mathrm{s}\right)$ is higher than that in subjects aged $>30$ years $\left(0.47 \pm 0.08 \times 10^{-3} \mathrm{~mm}^{2} / \mathrm{s}\right) .{ }^{94}$ The correlation between decreasing ADC values and increasing age is higher in women $(\mathrm{r}=-0.581 ; p<0.001)$ than men, ${ }^{93,95,96}$ most likely due to age-related increase in marrow fat and decrease in marrow perfusion. Marrow ADC values also decrease from L1 to $\mathrm{L} 5$ in line with increasing fat and decreasing perfusion from the upper to the lower lumbar region. ${ }^{97}$

ADC values in middle-aged to elderly patients with normal BMD were $0.47 \pm 0.03$; those with osteopenia were

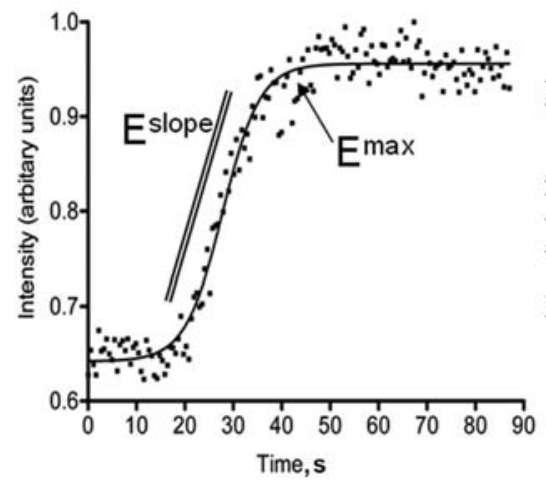

a

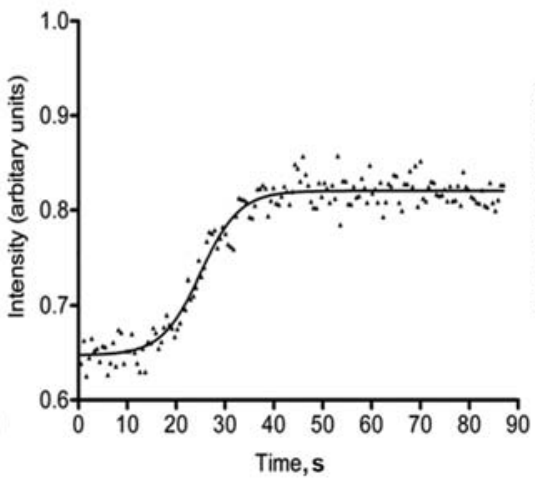

b Low bone mass

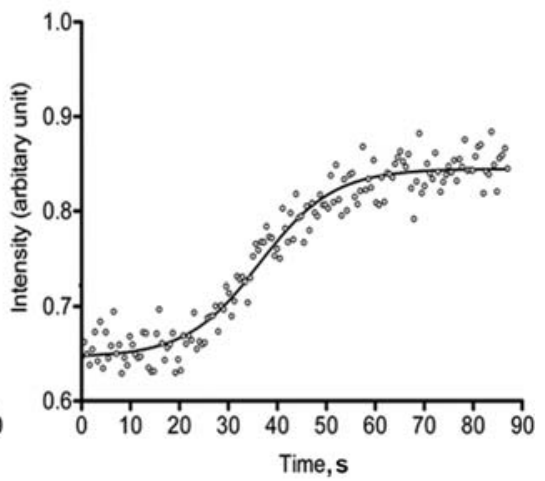

c Osteoporosis

Fig. 7 Typical time-intensity perfusion curves of vertebral body marrow perfusion from dynamic contrast-enhanced magnetic resonance imaging examination in subjects with (a) normal bone mineral density (BMD), (b) low bone mass (osteopenia), and (c) osteoporosis. The rate and degree of intravenous contrast in subjects with osteoporosis is less than in normal BMD subjects. Emax, maximal enhancement; Eslope, enhancement slope. 
$0.42 \pm 0.02$ and with osteoporosis were $0.39 \pm 0.03 .^{98}$ Similar differences were found by some ${ }^{72,99}$ but not all ${ }^{100}$ other studies, probably related to different examination protocols, analytical methods, and cohorts. ${ }^{73}$

\section{Bone Marrow Metabolism}

Based on the degree of glucose utilization, fluorodeoxyglucose accumulation provides a measure of tissue metabolic activity and, as such, can be used as a useful measure of bone marrow metabolic activity. ${ }^{101}$ Combining volumetric MRI data and quantitative metabolic data from positron emission tomography (PET) to calculate the relative metabolic activity of red and yellow marrow in the L1, L3, and L5 vertebral bodies, the mean maximum standardized uptake $\left(\mathrm{SUV}_{\max }\right)$ of fat and red marrow was $0.38 \pm 0.1$ and $2.6 \pm 0.6$, respectively. In other words, metabolic activity of red marrow was seven times that of fatty marrow. ${ }^{102}$ Bone marrow metabolic activity tended to decrease with age more in the proximal femora and humeri $(\mathrm{r}=-0.60$ to $-0.67 ; p<0.01)$ than the axial skeletal (sternal manubrium, 12th thoracic, 5th lumbar vertebra, and iliac crests) correlation coefficient -0.28 to -0.48 ; $p<0.05$ ). ${ }^{103}$

A ${ }^{18} \mathrm{~F}-\mathrm{NaF}$ PET/CT provides a specific measure of mineralized bone, rather than bone marrow metabolism and can also quantify arterial calcification. ${ }^{104,105}$ Analyzing this tracer uptake in patients undergoing ${ }^{18} \mathrm{~F}-\mathrm{NaF}$ PET/CT for suspected bone metastases, $\mathrm{SUV}_{\text {mean }}$ in the lumbar spine was $6.9 \pm 1.9$ (2.2-14.4), which was several times higher than the femoral neck, $2.7 \pm 1.0(0.9-8.0) .{ }^{100}$ Mean regional bone metabolism at the lumbar spine and femoral neck decreased with increasing age $(r=-0.44 ; p<0.001)$ and overall was lower in female patients. ${ }^{100}$ Bone mineral metabolism was also negatively correlated with hypertension ( $p=0.003$ ), hypercholesterolemia $(p=0.01)$, and prior cardiovascular events, which is not surprising given the well-known association between osteoporosis and arteriosclerosis, particularly arterial calcification. ${ }^{100,106}$

\section{Disk Volume and Degeneration}

Disk volume is relevant to the study of disk degeneration and other aspects of spinal pathology. ${ }^{107}$ The volume of a normal lumbar intervertebral disk is $\sim 10 \mathrm{~cm}^{3}$ when measured in the evening and $\sim 11 \mathrm{~cm}^{3}$ when measuring in the morning after a night's rest. In other words, the disk, through the effect of its hydrophilic proteoglycan molecules, attaches $\sim 0.9 \mathrm{~cm}^{3}$ of water into the disk overnight. Hence people are slightly taller in the morning and astronauts in space, who lack this cyclical fluid flow as a result of microgravity, lose height and have back pain. In osteoporotic and low bone mass patients, while central disk height is increased, giving rise to the biconcave appearance, overall lumbar disk volume is actually reduced compared with normal BMD patients. ${ }^{108}$ This may be due to compromised nutritional supply from the neighboring vertebrae as BMD decreases. ${ }^{108}$

To improve the quantification of disk degeneration, surrogate MR measures of tissue hydration, such as T1-, T2-, and T2* relaxation times, and T1 $\rho$ have been investigated. Diskal T2 relaxation times decrease with disk hydration and, to a lesser extent, with reduced proteoglycan and collagen con- tent. ${ }^{109-112} \mathrm{~T} 2$ relaxation provides a continuous measure of small changes in disk composition over time such as diurnal variation in disk water content ${ }^{112}$ and the effect of normal aging. ${ }^{112,113} \mathrm{~T} 2$ relaxation times of the nucleus pulposus decrease $\sim 10 \%$ per decade with physiologic aging. ${ }^{113}$ Overall disk T2 relaxation time tends to be lower in chronic low back pain patients than in symptomatic controls, especially in the posterior annulus fibrosus. ${ }^{114}$ This heightens the importance of addressing different areas of the disk when comparing different cohorts. On T2-weighted images, T2 or T1 $\rho$ maps, both the nucleus pulposus and the inner fibers of the annulus fibrosus have comparable signal intensity because the boundary between these two components of the disk is indistinct.

Several methods have been described to demarcate the nucleus and annulus on MR images, either based on visual assessment or quantitative measures based on equal areas of five or seven ROIs placed horizontally across the disk, with or without an intervening gap. The central three ROIs are usually defined as the nucleus pulposus. Visual assessment seems to produce a more reliable delineation of the nucleus and annulus than quantitative delineation. ${ }^{115} \mathrm{~T} 1 \rho$ relaxation measurement, which probes the interaction between water molecules and their macromolecular environment, has the potential to identify early biochemical changes in the disk, although the specific determinants of $\mathrm{T} 1 \rho$ relaxation are not well understood. T1 $\rho$ mapping may be slightly more sensitive than T2 mapping for disk degeneration, although it is more time consuming. Both T2 and T1 $\rho$ have a floor effect such that with more severe degeneration neither T2 or T1 $\rho$ measurements will change. Differences in T1 $\rho$ values between healthy and degenerative disks can be small, whereas errors in T1 $\rho$ quantification are many including B1 RF inhomogeneity and $B 0$ field inhomogeneity as well as data acquisition. This limits its clinical application as does the current lack of validation with a reference standard. ${ }^{116}$

\section{Ligamentum Flavum Thickness}

The ligamentum flavum extends from $\mathrm{C} 2$ to $\mathrm{S} 1$, bridging the anteroinferior part of the more cephalad lamina to the posterosuperior aspect of the more caudad lamina. It prevents separation of the posterior elements during spinal flexion and restores an erect posture after flexion. With increasing age, there is reduced elasticity of the ligament with an increase in the collagen and a decrease in the elastic fiber content. Most ligamentum flavum hypertrophy is caused by reduced disk height bulking the ligament rather than true hypertrophy of the ligament. ${ }^{107,117}$ Hypertrophy of the ligamentum flavum reduces the size of the central canal, lateral recesses, and exit foramina, compressing the descending and exiting nerve roots, and leading to radiculopathy. Average thickness of the ligamentum flavum in the cervical spine is $2.2 \pm 0.4 \mathrm{~mm}$, thinnest at $\mathrm{C} 2-\mathrm{C} 3$ and thickest in the lower cervical region. ${ }^{118}$

Average thickness of the ligamentum flavum in the thoracic region is $2.6 \pm 0.7 \mathrm{~mm}$, thinnest in the upper and thickest in the mid- to lower thoracic region. ${ }^{119}$ No age variation was apparent. ${ }^{119}$ Maximum thickness of the ligamentum flavum in the thoracic spine is at the T10-T11 level $(3.3 \pm 0.9 \mathrm{~mm})$, 

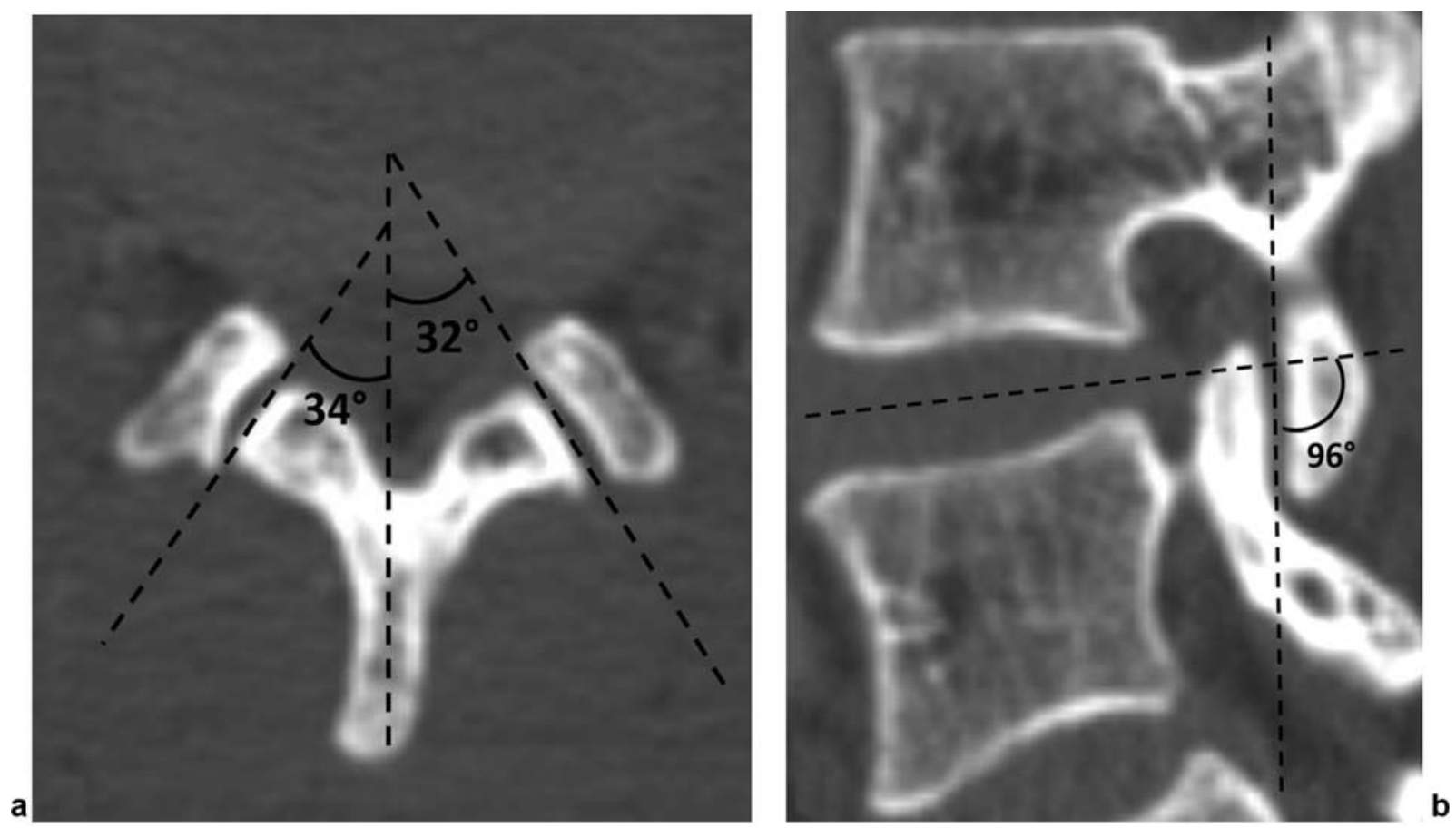

Fig. 8 The axial facet joint angle is typically measured between the mid-vertebral body sagittal line and a line drawn between the anteromedial and posterolateral edges of the superior articular facet at the disk level. In this example, the angles are 32 degrees and 34 degrees. There is no facet joint tropism. The sagittal angle is measured as the angle between a line bisecting the intervertebral disk and one drawn between the superior and inferior aspects of the facet joint. In this example, the angle is 96 degrees.

possibly due to larger tensile forces and mobility at this level. ${ }^{119}$ In the lumbar spine, ligamentum flavum thickness $>4 \mathrm{~mm}$ is considered hypertrophy. ${ }^{102,120}$ The ligamentum flavum tends to be thickest at L4-L5 followed by L5-S1 and is $\sim 5$ to $10 \%$ thicker on the left side. ${ }^{121}$

\section{Facet Joint Orientation}

Facet joint orientation/asymmetry is relevant to spinal biomechanics and seems to be related to the development of spondylolisthesis. ${ }^{122}$

The axial facet joint angle is typically measured either between the mid-vertebral body sagittal line and a line drawn between the anteromedial and posterolateral edges of the superior articular facet at the disk level ${ }^{122}$ ( - Fig. 8). Normally, the facet joint angle moves away from the midsagittal line, from an average of $\sim 42$ to 58 degrees while descending the lumbar spine. ${ }^{102}$

In a population study, using data deemed from routine abdominopelvic $\mathrm{CT}$ examinations, and defining spondylolisthesis as an intervertebral body shift $>7 \%$ of the AP diameter of the inferior vertebral body, spondylolisthesis was present in $8.7 \%$ of males and $16.4 \%$ of females, and most prevalent at L4-L5. ${ }^{122}$ Facet joint angles in the axial plane decreased, on average, with age in women but not in men, from $\sim 48$ to 43 degrees at L4-L5 and from $\sim 53$ to 47 degrees at L5-S1. ${ }^{122}$ Facet joint angles in the sagittal plane decreased in men more than women ${ }^{122}$ (- Fig. 8). This sagittal decrease in men was from $\sim 83$ to 80 degrees at L3-L4 and from $\sim 81$ to 79 degrees at L4-L5. ${ }^{122}$ This sagittalization and axialization of the facet joint with age may help explain why older people are more prone to degenerative spondylolisthesis. ${ }^{122}$

Facet joint tropism refers to facet joint angle symmetry. Facet joint trophism is considered acceptable if the side-to side difference in facet joint angles in either the axial or the sagittal plane is $<7$ degrees. ${ }^{122}$ Facet joint tropism in the axial plane is considered moderate if the difference is 7 to 15 degrees and severe if the difference is $>15$ degrees. ${ }^{102}$ Facet joint trophism is most severe at L4-L5, where a $20 \%$ prevalence of moderate and a $6 \%$ prevalence of severe trophism can exist. ${ }^{102}$ Also, patients with degenerative spondylolisthesis tend to have more facet joint tropism. ${ }^{122}$

In conclusion, we can appreciate how the many aspects of spine anatomy and physiology make it particularly conducive to quantitative analysis. Quantitative analysis of spine imaging data has begun to provide us with a much better understanding of spinal disease. More standardized analytics methods will allow more ready comparison of research studies with radiologists in a great position to drive this research forward.

Conflict of Interest

None declared.

\section{References}

1 Weaver O, Leung JWT. Biomarkers and imaging of breast cancer. AJR Am J Roentgenol 2018;210(02):271-278

2 Whyte MB, Kelly P. The normal range: it is not normal and it is not a range. Postgrad Med J 2018;94(1117):613-616 
3 Flechtner-Mors M, Schwab KO, Fröhlich-Reiterer EE, et al. Overweight and obesity based on four reference systems in 18,382 paediatric patients with type 1 diabetes from Germany and Austria. J Diabetes Res 2015;2015:370753

4 Ulbrich EJ, Schraner C, Boesch C, et al. Normative MR cervical spinal canal dimensions. Radiology 2014;271(01):172-182

5 Kato F, Yukawa Y, Suda K, Yamagata M, Ueta T. Normal morphology, age-related changes and abnormal findings of the cervical spine. Part II: Magnetic resonance imaging of over 1,200 asymptomatic subjects. Eur Spine J 2012;21(08):1499-1507

6 Fradet L, Arnoux PJ, Ranjeva JP, Petit Y, Callot V. Morphometrics of the entire human spinal cord and spinal canal measured from in vivo high-resolution anatomical magnetic resonance imaging. Spine 2014;39(04):E262-E269

7 Matsuura P, Waters RL, Adkins RH, Rothman S, Gurbani N, Sie I. Comparison of computerized tomography parameters of the cervical spine in normal control subjects and spinal cord-injured patients. J Bone Joint Surg Am 1989;71(02):183-188

8 American College of Radiology. Practice parameter for the performance of quantitative computed tomography (QCT) bone densitometry. Available at: https://www.acr.org/QualitySafety/Standards-Guidelines/Practice-Guidelines-by-Modality/ CT. Accessed April 12, 2020

9 Zhang JT, Wang LF, Liu YJ, et al. Relationship between developmental canal stenosis and surgical results of anterior decompression and fusion in patients with cervical spondylotic myelopathy. BMC Musculoskelet Disord 2015;16:267

10 Kadoya S, Nakamura T, Kwak R, Hirose G. Anterior osteophytectomy for cervical spondylotic myelopathy in developmentally narrow canal. J Neurosurg 1985;63(06):845-850

11 Nouri A, Martin AR, Nater A, et al. Influence of magnetic resonance imaging features on surgical decision-making in degenerative cervical myelopathy: results from a global survey of AOSpine international members. World Neurosurg 2017;105:864-874

12 Morishita Y, Naito M, Hymanson H, Miyazaki M, Wu G, Wang JC. The relationship between the cervical spinal canal diameter and the pathological changes in the cervical spine. Eur Spine J 2009; 18(06):877-883

13 Nagata K, Yoshimura N, Hashizume $\mathrm{H}$, et al. The prevalence of cervical myelopathy among subjects with narrow cervical spinal canal in a population-based magnetic resonance imaging study: the Wakayama Spine Study. Spine J 2014;14(12):2811-2817

14 Blackley HR, Plank LD, Robertson PA. Determining the sagittal dimensions of the canal of the cervical spine. The reliability of ratios of anatomical measurements. J Bone Joint Surg Br 1999;81 (01):110-112

15 Herzog RJ, Wiens JJ, Dillingham MF, Sontag MJ. Normal cervical spine morphometry and cervical spinal stenosis in asymptomatic professional football players. Plain film radiography, multiplanar computed tomography, and magnetic resonance imaging. Spine 1991;16(06):S178-S186

16 Prasad SS, O'Malley M, Caplan M, Shackleford IM, Pydisetty RK. MRI measurements of the cervical spine and their correlation to Pavlov's ratio. Spine 2003;28(12):1263-1268

17 Nakashima H, Yukawa Y, Suda K, Yamagata M, Ueta T, Kato F. Narrow cervical canal in 1211 asymptomatic healthy subjects: the relationship with spinal cord compression on MRI. Eur Spine J 2016;25(07):2149-2154

18 Hayashi H, Okada K, Hamada M, Tada K, Ueno R. Etiologic factors of myelopathy. A radiographic evaluation of the aging changes in the cervical spine. Clin Orthop Relat Res 1987;(214):200-209

19 Inoue H, Ohmori K, Takatsu T, Teramoto T, Ishida Y, Suzuki K. Morphological analysis of the cervical spinal canal, dural tube and spinal cord in normal individuals using CT myelography. Neuroradiology 1996;38(02):148-151

20 Kasai Y, Akeda K, Uchida A. Physical characteristics of patients with developmental cervical spinal canal stenosis. Eur Spine J 2007;16(07):901-903
21 Kim G, Khalid F, Oommen VV, et al. T1- vs. T2-based MRI measures of spinal cord volume in healthy subjects and patients with multiple sclerosis. BMC Neurol 2015;15:124

22 Ishikawa M, Matsumoto M, Fujimura Y, Chiba K, Toyama Y. Changes of cervical spinal cord and cervical spinal canal with age in asymptomatic subjects. Spinal Cord 2003;41(03):159-163

23 Kameyama T, Hashizume Y, AndoT, Takahashi A. Morphometry of the normal cadaveric cervical spinal cord. Spine 1994;19(18):2077-2081

24 Lee MJ, Cassinelli EH, Riew KD. Prevalence of cervical spine stenosis. Anatomic study in cadavers. J Bone Joint Surg Am 2007;89(02):376-380

25 Yanase M, Matsuyama Y, Hirose K, et al. Measurement of the cervical spinal cord volume on MRI. J Spinal Disord Tech 2006;19 (02):125-129

26 Sayıt E, Aghdasi B, Daubs MD, Wang JC. The occupancy of the components in the cervical spine and their changes with extension and flexion. Global Spine J 2015;5(05):396-405

27 Rüegg TB, Wicki AG, Aebli N, Wisianowsky C, Krebs J. The diagnostic value of magnetic resonance imaging measurements for assessing cervical spinal canal stenosis. J Neurosurg Spine 2015;22(03):230-236

28 Nouri A, Montejo J, Sun X, et al. Cervical cord-canal mismatch: a new method for identifying predisposition to spinal cord injury. World Neurosurg 2017;108:112-117

29 Countee RW, Vijayanathan T. Congenital stenosis of the cervical spine: diagnosis and management. J Natl Med Assoc 1979;71 (03):257-264

30 Nouri A, Martin AR, Tetreault L, et al. MRI analysis of the combined prospectively collected AOSpine North America and international data: the prevalence and spectrum of pathologies in a global cohort of patients with degenerative cervical myelopathy. Spine 2017;42(14):1058-1067

31 Nouri A, Tetreault L, Nori S, Martin AR, Nater A, Fehlings MG. Congenital cervical spine stenosis in a multicenter global cohort of patients with degenerative cervical myelopathy: an ambispective report based on a magnetic resonance imaging diagnostic criterion. Neurosurgery 2018;83(03):521-528

32 Presciutti SM, DeLuca P, Marchetto P, Wilsey JT, Shaffrey C, Vaccaro AR. Mean subaxial space available for the cord index as a novel method of measuring cervical spine geometry to predict the chronic stinger syndrome in American football players. J Neurosurg Spine 2009;11(03):264-271

33 Tierney RT, Maldjian C, Mattacola CG, Straub SJ, Sitler MR. Cervical spine stenosis measures in normal subjects. J Athl Train 2002;37(02):190-193

34 Ezra D, Masharawi Y, Salame K, Slon V, Alperovitch-Najenson D, Hershkovitz I. Demographic aspects in cervical vertebral bodies' size and shape (C3-C7): a skeletal study. Spine J 2017;17(01): 135-142

35 Stemper BD, Yoganandan N, Pintar FA, et al. Anatomical gender differences in cervical vertebrae of size-matched volunteers. Spine 2008;33(02):E44-E49

36 Pashkova IG, Kosourov AK. Age dependent changes in cervical region of the spine according to data of nuclear magnetic tomography. [in Russian]. Morfologiia 2004;125(01):80-82

37 Boyle JW, Nikitov SA, Boardman AD, Booth JG, Booth K. Nonlinear self-channeling and beam shaping of magnetostatic waves in ferromagnetic films. Phys Rev B Condens Matter 1996;53(18): 12173-12181

38 Papp T, Porter RW, Craig CE, Aspden RM, Campbell DM. Significant antenatal factors in the development of lumbar spinal stenosis. Spine 1997;22(16):1805-1810

39 Schizas C, Schmit A, Schizas A, Becce F, Kulik G, Pierzchała K. Secular changes of spinal canal dimensions in western Switzerland: a narrowing epidemic? Spine 2014;39(17):1339-1344

40 Griffith JF, Huang J, Law SW, et al. Population reference range for developmental lumbar spinal canal size. Quant Imaging Med Surg 2016;6(06):671-679 
41 Wiley MR, Hee Jo C, Khaleel MA, McIntosh AL. Size matters: which adolescent patients are most likely to require surgical decompression for lumbar disk herniations? J Pediatr Orthop 2019;39(10):e791-e795

42 Steurer J, Roner S, Gnannt R, Hodler J; LumbSten Research Collaboration. Quantitative radiologic criteria for the diagnosis of lumbar spinal stenosis: a systematic literature review. BMC Musculoskelet Disord 2011;12:175

43 Limthongkul W, Karaikovic EE, Savage JW, Markovic A. Volumetric analysis of thoracic and lumbar vertebral bodies. Spine J 2010;10(02):153-158

44 Wilms GE, Willems E, Demaerel P, De Keyzer F. CT volumetry of lumbar vertebral bodies in patients with hypoplasia L5 and bilateral spondylolysis and in normal controls. Neuroradiology 2012;54(08):839-843

45 Caula A, Metmer G, Havet E. Anthropometric approach to lumbar vertebral body volumes. Surg Radiol Anat 2016;38(03):303-308

46 Griffith JF, Engelke K, Genant HK. Looking beyond bone mineral density : Imaging assessment of bone quality. Ann N Y Acad Sci 2010;1192:45-56

47 Löffler MT, Sollmann N, Mei K, et al. X-ray-based quantitative osteoporosis imaging at the spine. Osteoporos Int 2020;31(02): 233-250

48 Adams JE. Quantitative computed tomography. Eur J Radiol 2009;71(03):415-424

49 Roski F, Hammel J, Mei K, et al. Bone mineral density measurements derived from dual-layer spectral CT enable opportunistic screening for osteoporosis. Eur Radiol 2019;29(11):6355-6363

50 Sfeir JG, Drake MT, Atkinson EJ, et al. Evaluation of crosssectional and longitudinal changes in volumetric bone mineral density in postmenopausal women using single- versus dualenergy quantitative computed tomography. Bone 2018; 112:145-152

51 Cheng X, Li K, Zhang Y, et al. The accurate relationship between spine bone density and bone marrow in humans. Bone 2020; 134:115312

52 Bredella MA, Daley SM, Kalra MK, Brown JK, Miller KK, Torriani M. Marrow adipose tissue quantification of the lumbar spine by using dual-energy CT and single-voxel (1)H MR spectroscopy: a feasibility study. Radiology 2015;277(01):230-235

53 Ulano A, Bredella MA, Burke P, et al. Distinguishing untreated osteoblastic metastases from enostoses using CT attenuation measurements. AJR Am J Roentgenol 2016;207(02):362-368

54 Sala F, Dapoto A, Morzenti C, et al. Bone islands incidentally detected on computed tomography: frequency of enostosis and differentiation from untreated osteoblastic metastases based on CT attenuation value. Br J Radiol 2019;92(1103):20190249

55 Dieckmeyer $M$, Ruschke $S$, Cordes $C$, et al. The need for $T_{2}$ correction on MRS-based vertebral bone marrow fat quantification: implications for bone marrow fat fraction age dependence. NMR Biomed 2015;28(04):432-439

56 Kühn JP, Hernando D, Meffert PJ, et al. Proton-density fat fraction and simultaneous R2* estimation as an MRI tool for assessment of osteoporosis. Eur Radiol 2013;23(12):3432-3439

57 Zhang Y, Zhou Z, Wang C, et al. Reliability of measuring the fat content of the lumbar vertebral marrow and paraspinal muscles using MRI mDIXON-Quant sequence. Diagn Interv Radiol 2018; 24(05):302-307

58 Karampinos DC, Baum T, Nardo L, et al. Characterization of the regional distribution of skeletal muscle adipose tissue in type 2 diabetes using chemical shift-based water/fat separation. J Magn Reson Imaging 2012;35(04):899-907

59 Bernard CP, Liney GP, Manton DJ, Turnbull LW, Langton CM. Comparison of fat quantification methods: a phantom study at 3.0T. J Magn Reson Imaging 2008;27(01):192-197

60 Griffith JF, Yeung DK, Chow SK, Leung JC, Leung PC. Reproducibility of MR perfusion and (1)H spectroscopy of bone marrow. J Magn Reson Imaging 2009;29(06):1438-1442
61 Baum T, Yap SP, Dieckmeyer M, et al. Assessment of whole spine vertebral bone marrow fat using chemical shift-encoding based water-fat MRI. J Magn Reson Imaging 2015;42(04):1018-1023

62 Sieron D, Drakopoulos D, Loebelenz LI, et al. Correlation between fat signal ratio on T1-weighted MRI in the lower vertebral bodies and age, comparing 1.5-T and 3-T scanners. Acta Radiol Open 2020;9(01):2058460120901517

63 Belavy DL, Quittner MJ, Ridgers ND, Shiekh A, Rantalainen T, Trudel G. Specific modulation of vertebral marrow adipose tissue by physical activity. J Bone Miner Res 2018;33(04):651-657

64 Kugel H, Jung C, Schulte O, Heindel W. Age- and sex-specific differences in the $1 \mathrm{H}$-spectrum of vertebral bone marrow. J Magn Reson Imaging 2001;13(02):263-268

65 Duda SH, Laniado M, Schick F, Strayle M, Claussen CD. Normal bone marrow in the sacrum of young adults: differences between the sexes seen on chemical-shift MR imaging. AJR Am J Roentgenol 1995;164(04):935-940

66 Griffith JF, Yeung DKW, Ma HT, Leung JC, Kwok TCY, Leung PC. Bone marrow fat content in the elderly: a reversal of sex difference seen in younger subjects. J Magn Reson Imaging 2012;36(01):225-230

67 Griffith JF, Wang YX, Zhou H, et al. Reduced bone perfusion in osteoporosis: likely causes in an ovariectomy rat model. Radiology 2010;254(03):739-746

68 Griffith JF, Yeung DK, Ahuja AT, et al. A study of bone marrow and subcutaneous fatty acid composition in subjects of varying bone mineral density. Bone 2009;44(06):1092-1096

69 Griffith JF. Age-related changes in the bone marrow. Curr Radiol Rep 2017;5:24

70 Dunnill MS, Anderson JA, Whitehead R. Quantitative histological studies on age changes in bone. J Pathol Bacteriol 1967;94(02): 275-291

71 Griffith JF, Yeung DK, Antonio GE, et al. Vertebral bone mineral density, marrow perfusion, and fat content in healthy men and men with osteoporosis: dynamic contrast-enhanced MR imaging and MR spectroscopy. Radiology 2005;236(03):945-951

72 Griffith JF, Yeung DK, Antonio GE, et al. Vertebral marrow fat content and diffusion and perfusion indexes in women with varying bone density: MR evaluation. Radiology 2006;241(03): 831-838

73 Li X, Shet K, Xu K, Rodríguez JP, Pino AM, Kurhanewicz J, Schwartz A, Rosen CJ. Unsaturation level decreased in bone marrow fat of postmenopausal women with low bone density using high resolution magic angle spinning (HRMAS) $1 \mathrm{H}$ NMR spectroscopy. Bone. 2017;105:87-92

74 Griffith JF, Yeung DK, Leung JC, Kwok TC, Leung PC. Prediction of bone loss in elderly female subjects by MR perfusion imaging and spectroscopy. Eur Radiol 2011;21(06):1160-1169

75 Woods GN, Ewing SK, Sigurdsson S, et al. Greater bone marrow adiposity predicts bone loss in older women. J Bone Miner Res 2020;35(02):326-332

76 Wehrli FW, Hopkins JA, Hwang SN, Song HK, Snyder PJ, Haddad JG. Cross-sectional study of osteopenia with quantitative MR imaging and bone densitometry. Radiology 2000;217(02):527-538

77 Griffith JF. Identifying osteoporotic vertebral fracture. Quant Imaging Med Surg 2015;5(04):592-602

78 Schmeel FC, Luetkens JA, Feißt A, et al. Quantitative evaluation of $\mathrm{T}^{*}$ relaxation times for the differentiation of acute benign and malignant vertebral body fractures. Eur J Radiol 2018;108:59-65

79 Suh CH, Yun SJ, Jin W, Park SY, Ryu CW, Lee SH. Diagnostic performance of in-phase and opposed-phase chemical-shift imaging for differentiating benign and malignant vertebral marrow lesions: a meta-analysis. AJR Am J Roentgenol 2018; 211(04):W188-W197

80 Yeung DK, Griffith JF, Antonio GE, Lee FK, Woo J, Leung PC. Osteoporosis is associated with increased marrow fat content and decreased marrow fat unsaturation: a proton MR spectroscopy study. J Magn Reson Imaging 2005;22(02):279-285 
81 Patsch JM, Li X, Baum T, et al. Bone marrow fat composition as a novel imaging biomarker in postmenopausal women with prevalent fragility fractures. J Bone Miner Res 2013;28(08):1721-1728

82 Chen WT, Ting-Fang Shih T, Hu CJ, Chen RC, Tu HY. Relationship between vertebral bone marrow blood perfusion and common carotid intima-media thickness in aging adults. J Magn Reson Imaging 2004;20(05):811-816

83 Chen WT, Shih TT, Chen RC, et al. Vertebral bone marrow perfusion evaluated with dynamic contrast-enhanced MR imaging: significance of aging and sex. Radiology 2001;220(01):213-218

84 Montazel JL, Divine M, Lepage E, Kobeiter H, Breil S, Rahmouni A. Normal spinal bone marrow in adults: dynamic gadoliniumenhanced MR imaging. Radiology 2003;229(03):703-709

85 Savvopoulou V, Maris TG, Vlahos L, Moulopoulos LA. Differences in perfusion parameters between upper and lower lumbar vertebral segments with dynamic contrast-enhanced MRI (DCE MRI). Eur Radiol 2008;18(09):1876-1883

86 Hillengass J, Stieltjes B, Bäuerle T, et al. Dynamic contrastenhanced magnetic resonance imaging (DCE-MRI) and diffusion-weighted imaging of bone marrow in healthy individuals. Acta Radiol 2011;52(03):324-330

87 Baur A, Stäbler A, Bartl R, Lamerz R, Scheidler J, Reiser M. MRI gadolinium enhancement of bone marrow: age-related changes in normals and in diffuse neoplastic infiltration. Skeletal Radiol 1997;26(07):414-418

88 Griffith JF, Yeung DK, Tsang PH, et al. Compromised bone marrow perfusion in osteoporosis. J Bone Miner Res 2008;23(07): 1068-1075

89 Wang YX, Griffith JF, Kwok AW, et al. Reduced bone perfusion in proximal femur of subjects with decreased bone mineral density preferentially affects the femoral neck. Bone 2009;45(04): 711-715

90 Biffar A, Dietrich O, Sourbron S, Duerr HR, Reiser MF, BaurMelnyk A. Diffusion and perfusion imaging of bone marrow. Eur J Radiol 2010;76(03):323-328

91 Ward R, Caruthers S, Yablon C, Blake M, DiMasi M, Eustace S. Analysis of diffusion changes in posttraumatic bone marrow using navigator-corrected diffusion gradients. AJR Am J Roentgenol 2000;174(03):731-734

92 Li X, Schwartz AV. MRI assessment of bone marrow composition in osteoporosis. Curr Osteoporos Rep 2020;18(01):57-66

93 Jie H, Hao F, Na LX. Vertebral bone marrow diffusivity in healthy adults at 3T diffusion-weighted imaging. Acta Radiol 2016;57 (10):1238-1243

94 Herrmann J, Krstin N, Schoennagel BP, et al. Age-related distribution of vertebral bone-marrow diffusivity. Eur J Radiol 2012; 81(12):4046-4049

95 Yeung DK, Wong SY, Griffith JF, Lau EM. Bone marrow diffusion in osteoporosis: evaluation with quantitative MR diffusion imaging. J Magn Reson Imaging 2004;19(02):222-228

96 Nonomura Y, Yasumoto M, Yoshimura R, et al. Relationship between bone marrow cellularity and apparent diffusion coefficient. J Magn Reson Imaging 2001;13(05):757-760

97 Lasbleiz J, Le Ster C, Guillin R, Saint-Jalmes H, Gambarota G. Measurements of diffusion and perfusion in vertebral bone marrow using intravoxel incoherent motion (IVIM) with multishot, readout-segmented (RESOLVE) echo-planar imaging. J Magn Reson Imaging 2019;49(03):768-776

98 Hatipoglu HG, Selvi A, Ciliz D, Yuksel E. Quantitative and diffusion MR imaging as a new method to assess osteoporosis. AJNR Am J Neuroradiol 2007;28(10):1934-1937

99 Tang GY, Lv ZW, Tang RB, et al. Evaluation of MR spectroscopy and diffusion-weighted MRI in detecting bone marrow changes in postmenopausal women with osteoporosis. Clin Radiol 2010; 65(05):377-381

100 Shih TT, Liu HC, Chang CJ, Wei SY, Shen LC, Yang PC. Correlation of MR lumbar spine bone marrow perfusion with bone mineral density in female subjects. Radiology 2004;233(01):121-128
101 Blebea JS, Houseni M, Torigian DA, et al. Structural and functional imaging of normal bone marrow and evaluation of its agerelated changes. Semin Nucl Med 2007;37(03):185-194

102 Basu S, Houseni M, Bural G, et al. Magnetic resonance imaging based bone marrow segmentation for quantitative calculation of pure red marrow metabolism using 2-deoxy-2-[F-18]fluoro-Dglucose-positron emission tomography: a novel application with significant implications for combined structure-function approach. Mol Imaging Biol 2007;9(06):361-365

103 Fan C, Hernandez-Pampaloni M, Houseni M, et al. Age-related changes in the metabolic activity and distribution of the red marrow as demonstrated by 2-deoxy-2-[F-18]fluoro-D-glucosepositron emission tomography. Mol Imaging Biol 2007;9(05): 300-307

104 Derlin T, Janssen T, Salamon J, et al. Age-related differences in the activity of arterial mineral deposition and regional bone metabolism: a 18F-sodium fluoride positron emission tomography study. Osteoporos Int 2015;26(01):199-207

105 Kurata S, Shizukuishi K, Tateishi U, et al. Age-related changes in pre- and postmenopausal women investigated with $18 \mathrm{~F}-$ fluoride PET-a preliminary study. Skeletal Radiol 2012;41(08): 947-953

106 Griffith JF, Kumta SM, Huang Y. Hard arteries, weak bones. Skeletal Radiol 2011;40(05):517-521

107 Sudhir G, Vignesh Jayabalan S, Gadde S, Venkatesh Kumar G, Karthik Kailash K. Analysis of factors influencing ligamentum flavum thickness in lumbar spine: a radiological study of 1070 disc levels in 214 patients. Clin Neurol Neurosurg 2019; 182:19-24

108 Kwok AW, Wang YX, Griffith JF, et al. Morphological changes of lumbar vertebral bodies and intervertebral discs associated with decrease in bone mineral density of the spine: a cross-sectional study in elderly subjects. Spine 2012;37(23):E1415-E1421

109 Tertti M, Paajanen H, Laato M, Aho H, Komu M, Kormano M. Disc degeneration in magnetic resonance imaging. A comparative biochemical, histologic, and radiologic study in cadaver spines. Spine 1991;16(06):629-634

110 Marinelli NL, Haughton VM, Muñoz A, Anderson PA. T2 relaxation times of intervertebral disc tissue correlated with water content and proteoglycan content. Spine 2009;34(05):520-524

111 Kerttula L, Kurunlahti M, Jauhiainen J, Koivula A, Oikarinen J, Tervonen 0 . Apparent diffusion coefficients and T2 relaxation time measurements to evaluate disc degeneration. A quantitative MR study of young patients with previous vertebral fracture. Acta Radiol 2001;42(06):585-591

112 Boos N, Wallin A, Gbedegbegnon T, Aebi M, Boesch C. Quantitative MR imaging of lumbar intervertebral disks and vertebral bodies: influence of diurnal water content variations. Radiology 1993;188(02):351-354

113 Marinelli NL, Haughton VM, Anderson PA. T2 relaxation times correlated with stage of lumbar intervertebral disk degeneration and patient age. AJNR Am J Neuroradiol 2010;31(07):1278-1282

114 Ogon I, Takebayashi T, Takashima H, et al. Analysis of chronic low back pain with magnetic resonance imaging T2 mapping of lumbar intervertebral disc. J Orthop Sci 2015;20(02):295-301

115 Mok GSP, Zhang D, Chen SZ, Yuan J, Griffith JF, Wang YXJ. Comparison of three approaches for defining nucleus pulposus and annulus fibrosus on sagittal magnetic resonance images of the lumbar spine. J Orthop Translat 2016;6:34-41

116 Wáng YX. Towards consistency for magnetic resonance (MR) relaxometry of lumbar intervertebral discs. Quant Imaging Med Surg 2016;6(04):474-477

117 Altinkaya N, Yildirim T, Demir S, Alkan O, Sarica FB. Factors associated with the thickness of the ligamentum flavum: is ligamentum flavum thickening due to hypertrophy or buckling? Spine 2011;36(16):E1093-E1097

118 Rahmani MS, Terai H, Akhgar J, et al. Anatomical analysis of human ligamentum flavum in the cervical spine: Special 
consideration to the attachments, coverage, and lateral extent. J Orthop Sci 2017;22(06):994-1000

119 Chelladurai A, Balasubramaniam S, Anbazhagan SP, Gnanasihamani S, Ramaswami S. Dorsal spinal ligamentum flavum thickening: a magnetic resonance imaging study. Asian Spine J 2018;12(01):47-51

120 Munns JJ, Lee JY, Espinoza Orías AA, et al. Ligamentum flavum hypertrophy in asymptomatic and chronic low back pain subjects. PLOS One 2015;10(05):e0128321
121 Kolte VS, Khambatta S, Ambiye MV. Thickness of the ligamentum flavum: correlation with age and its asymmetry-an magnetic resonance imaging study. Asian Spine J 2015;9(02): 245-253

122 Morimoto M, Higashino K, Manabe H, et al. Age-related changes in axial and sagittal orientation of the facet joints: Comparison with changes in degenerative spondylolisthesis. J Orthop Sci 2019;24(01):50-56 